\title{
Internet Accessible Remote Experimentation: Setting the Right Course of Action
}

\author{
doi:10.3991/ijoe.v6i3.1380 \\ Abul K. M. Azad \\ Northern Illinois University, Illinois, United States of America
}

\begin{abstract}
This paper will have two parts. In the first part the author will focus on the current status of remote experimentation designs and how this has impacted our education and research activities with a notion that whether we are moving too fast while its acceptance has not yet realized. While for the second part, the author will describe some of the developments of remote experiment designs through his own work.
\end{abstract}

Researchers have been working on remote experimentations for a considerable period of time and are making remarkable breakthroughs utilizing cutting edge technologies and current understanding of educational and learning strategies. After all of these developments, the popularity of remote experimentations is still very limited and does not have the attention of the academic community to incorporate them as a part of their regular curriculum. There are a number of factors that hinder acceptance of remote laboratories as a part of a curriculum. These are integration of a number of areas, modular designs, commercial products, maintenance, and administrative support. The paper will address these issues and will highlight how we can move forward in a coordinated manner so there will be a viable remote experimentation infrastructure with a high degree of acceptance.

The author has a number of federal research grants (USA) where he has developed Internet accessible remote experimentation facilities. These facilities have features like use of single computer for accessing multiple experiments, manipulating experimental setup from remote locations, integrated assessment, and real-time learning management features. The developed facilities have used for delivering a number of experiment courses, while gathering data in terms of achieving learning outcomes and assessing the effectiveness of the system in terms of system designs.

Index Terms-Online experiment, remote experimentation, distance learning, modularity in design, and learning management system.

\section{INTRODUCTION}

Attempts to use computer and computer-related technologies to enhance learning began with the efforts of pioneers such as Atkinson and Suppers [1, 2]. The presence of computer technology in education has increased dramatically since that time, and predictions are that this trend will continue to accelerate. Many of the new technologies are interactive, and it is now easier to create environments in which students can learn by doing, receive feedback, and continuously refine their understanding and build new knowledge [3]. The new technologies can also help people visualize difficult-to-understand concepts.

\section{A. Internet Technology in Education}

The Internet is now extensively used as a connectivity and reference tool for commercial, personal, and educational purposes [4, 5]. Education has opened a variety of new avenues and methodologies for enhancing the experience of learning as well as for expanding educational opportunities for a larger pool of students [6, 7]. Furthermore, it appears that on-line education will continue to evolve and that the process is irreversible $[8,9]$.

There are a number of initiatives where the Internet has been used for education and corporate training [10, 11, 12 , $13,14]$. In almost all cases, web courses are only based on theoretical/simulation materials [15, 16, 17, 18]. Although limited, even this offering of engineering and technology courses over the Internet has already proven to increase the student retention rate by providing diversity of choice and convenience [19, 20, 21].

It is also reported that in terms of learning outcome, the on-line method yields a higher level of efficiency than traditional lectures, despite the inherent drawbacks of the approach, such as lack of class interaction and the increased self-discipline required by the students $[10,11]$. The eArmy Initiative that brings the educational institution to every soldier, and allows them to continue with the same institution or an institution of choice, is a solution for success [12]. A low-cost collaborative learning environment has also been developed for virtual training that is suitable for corporate use [13]. This environment allows a facilitator, experts, and trainees to communicate and act in the virtual environment to practice skills during collaborative problem solving sessions. In another approach, the Internet has been used as a medium for teaching a foreign language since it can ensure that the audience may be located anywhere in the world [14].

\section{B. Internet Accessible Remote Experimentation}

Traditional experiment classes are scheduled only for a limited time period. Considering the mixed ability level of students, the allocated time is often not enough for all students to complete their tasks satisfactorily and also gain sufficient experience through the process [22, 23]. Sometimes students want or feel a need to perform additional experiments beyond their assigned tasks. It is usually difficult to accommodate any extra time due to the lack of available resources to keep the laboratories open. Additionally, experiment facilities are often inaccessible to the students of other departments within the same institution because of their geographical location. Ironically, too 
much experiment equipment lies idle during most of its usable lifetime [24, 25, 26].

Only a remote experimentation facility can provide cost effective and unlimited access to experiments and maximize the utilization of available resources. Moreover, this will allow inter-experiment collaboration among universities and research centers by providing research and student groups access to a wide collection of expensive experimental resources at geographically distant locations.

One of the major limitations of the existing Internet based distance-learning courses is their failure to deliver the experiment-related courses [16, 27]. While simulation and multimedia provide a good learning experience, for effective and complete learning, especially in STEM programs, a mixture of theoretical and practical sessions are needed. Currently, students from distance learning programs have to visit a campus to perform the experiment sessions within a limited period of time [20,4], which is usually insufficient to allow them to complete their learning cycle [22, 28]. Making the remote experiment experiments accessible through the Internet would address this problem.

With a burning need for an Internet accessible remote experiment and exponential advancement in Internet and computer technologies and instrumentation researchers/educators took the initiative to develop a number of remote experimentation facilities. Some recent initiatives have attempted to provide a couple of experiments on a dynamic systems experiment and a basic electronics experiment over the Internet [29, 30, 31, 32, 33, 34].

Having all these developments, the popularity of remote experimentations has not yet gathered momentum. The authors realized that a number of issues influence this scenario. The major issues are integration of a number of disciplines in remote experimentation design, lack of modular approach in designs, absence of readily available commercial products, maintenance issues, and insufficient administrative support.

The first part of the paper will discuss these issues and try to present a strategy that can be adopted to address these shortcomings. The second part of the paper will describe some of the remote experimentation developments that the first author has initiated through a number of federal and institutional grants. Some of these developments were used to offer experiment courses as a part of regular curriculum. Experiences from these course offerings will also be presented within the second part.

\section{STATE OF INTERNET ACCESSIBLE REMOTE EXPERIMENT}

\section{A. What are the issues}

Performing experiments (on real hardware) over the Internet is a relatively new concept. As mentioned in the introduction section, researchers are pursuing this problem in an abrupt manner and are not yet coming up with a sustainable solution that can popularize the use of remote laboratories. The major issues are:

a) Integration of a number of disciplines into remote experimentation design;

b) Modularity in designs;

c) Readily available commercial products;

d) Integration of learning management system;

e) Maintenance and training; f) Administrative awareness and support; and

g) Industry applications.

a) Integration of a number of disciplines into remote experimentation design: Any development within the Internet accessible remote experiment area warrants expertise from a number of disciplines. This includes computer interfacing, data acquisition and control, web application development, computer networking, web security, and real-time control. Symbolically this can be represented through a picture as shown in Figure 1. This is a brand new entity and no none is sure how to pursue this effectively.

Considering our compartmental arrangement of disciplines in education and research, it is usually difficult for a person or even a research/academic group to gather all this expertise, unless one deliberately forms a group with these capabilities, which is usually difficult for most of the research/academic institutions. Only a few research groups successful in assembling all these necessary expertise and developed Internet accessible remote experiments and delivered a powerful message by demonstrating the potential of this discipline.

b) Modularity in designs: The nature of experiments that need to be accessed via Internet various from discipline to discipline. In the academic/research areas, there are different kinds of experiments with a variety of inputs and outputs (in terms of frequency and voltage levels) along with need for data presentations. Having all these complex issues, it was difficult for most of the remote experiment designers to consider the modularity in system design. In general, there is an absence of any common framework, each development initiative starts from a scratch and there is difficulty in transferability of one component of a system to another or integration between the systems. This makes it difficult for an Internet accessible remote experiment to adapt with additional experiments or to interface with another remote experiment system. To accommodate new experiments one has to redesign the system. In this respect, some of the limitations of remote laboratories are reported some researchers [35].

c) Readily available commercial products: In recent years both the hardware and software technologies has been developed extensively, which has enabled the Internet accessible experiment designers to come up with more powerful systems that was not possible in the past. However, integration of these available technologies is a major issue and warrants some level of expertise that is not readily available to an institution. There is no commercial pro-

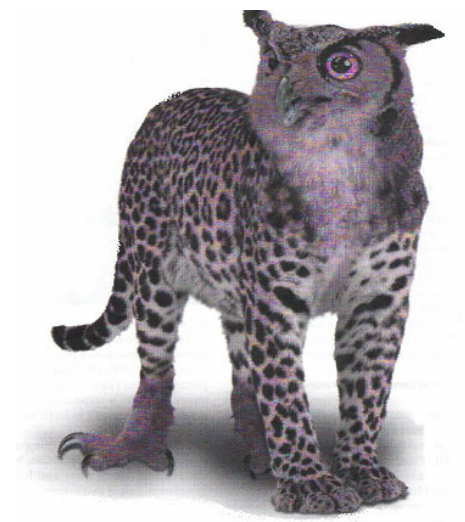

Figure 1. Symbolic presentation of remote experimentation systems. 
duct that is designed with Internet accessible remote experiment in mind so that one can design a system with offthe-shelf products. With this scenario, as it is no, developer of such systems is the only user as well. This hinders the creation of a user base, who likes and can use the facility without going into the design and implementation details. This is one of the major drawbacks for a sustainable development of this area.

d) Integration of learning management system (LMS): The Internet accessible remote experiment is a type of distance learning education and there is a desire to have an integrated LMS so that an academic can manage the learning process while delivering a remote experiment course. Most of the remote experiment designs do not have a LMS and need to incorporate an existing LMS such as Blackboard. These LMS systems are not designed to deal with applications like remote experimentations.

e) Maintenance and training: Considering the complexity of Internet accessible remote experiment system, it is difficult to find a maintenance technician who can understand and address the need for a system of this nature. In most cases, the developed system is maintained by graduate students or entry-level researchers, who are usually a moving entity. To address this issue it is important to develop training programs that can be a source of trained maintenance technician for remote experiment facilities.

f) Administrative awareness and support: A major drawback for the remote experimentation area is the lack of administrative awareness about the potential of this area. Not many leaders of academic community and institutional administrators in academic institutions realize the potential of Internet accessible remote laboratories. This is a major limitation for the sustainability issue of this area. In most of the cases, projects on remote laboratories are funded by national and regional agencies. At the end of a project, usually there is no follow-up investment from the home institution to sustain the development. This is due to the lack of understanding of potential of this area. To address this issue, it is important to initiate a campaign via professional organizations and public media. Only the awareness of the academic leaders and institutional administrators, who have control over the financial matter can ensure strong institutional support for remote experiment development and their sustainability.

g) Industry applications: Apart from few cases, most of the developments of Internet accessible remote experiments are designed with the educational applications in mind. Although the remote experimentation concept has enormous potential for industry applications, there is no active effort to explore these. The industry applications can be vital sign diagnosis by experts for industry manufacturing processes, disaster prevention, and training. With the globalization of industries, there is lack of experts who can ensure smooth operation of a plant. Remote experimentation concept has potential to play a vital role in this effort by providing the experts a real time access to the plant. It is important to mention here that the industry has financial power and any interest from industry towards this technology will attract development funding. This will be a major support towards the Internet accessible remote experimentation area.

\section{B. What Can be Done}

In the light of above discussion and looking from an overall prospective, it is true that the Internet accessible remote experiment area has exploited recent technological progress in software and hardware and enables to make remarkable improvements. Some of the current developments have features that were unthinkable couple of years back. However, the use of these facilities is very limited and most of the cases these are used for testing and validation purposes, very few systems were integrated into our regular educational infrastructure. So, one can ask a question: Are we in the right course? Is it not important for us to address few vital issues before we proceed further? With this notion and scenario the author has presented few important issues (in the previous section) that need to be addressed to make the use of Internet accessible remote experimentation widespread and sustainable. These are:

a) Standardization and modularity in design

b) Integration of learning management system

c) Training initiatives

d) Awareness initiatives

e) Industry applications

f) Commercial products

A concept of modularity in design is presented in Figure 2. The main modules are Interface module, Experiment server, Learning management system (LMS) server, and Local Network. To have a level of flexibility in operation, future expansion, and collaboration, there should be an understanding within the community for an interfacing standard between the modules. In this regard, recently, MIT took an initiative along with researchers and academics around the world to form a consortium to discuss on major developments in this area and come up with a broader framework for remote experiment development. This will streamline future developments through a modular design of system components with pre-determined inputs/outputs for each module. This kind of approach will foster intractability between the systems, ability to handle different kinds of experiments, and sharing of resources to maximize the use of available resources.

Creating manpower that can support the development and maintenance of Internet accessible remote experimentation is essential for this area. Every opportunity has to be utilized to develop academic and vocational training courses for remote experimentation.

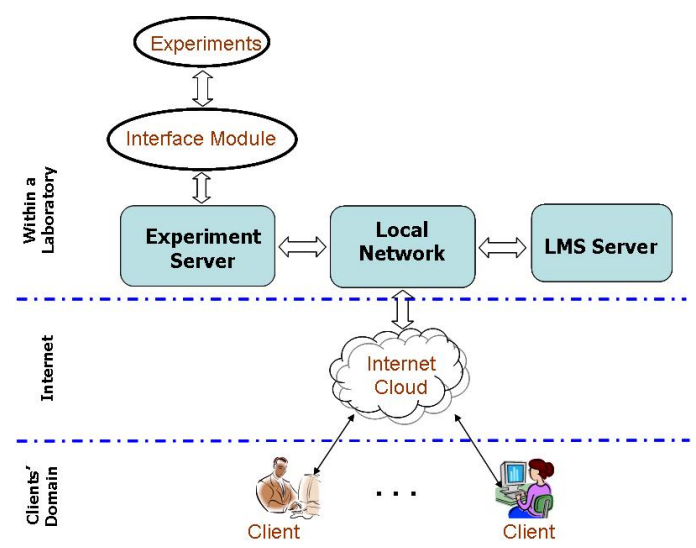

Figure 2. Concept of modularity in design of remote laboratories. 
Awareness about the potential of remote experimentation among the engineering, academic, and industry leaders is an essential step to attract research and development investment in this area. This includes engineering deans and higher academic administrators, professional organization leaders, and industry executives. These can involve personal meeting, articles in -journals, professional magazines, national and regional newspapers, and Internet sites, radio and TV shows. To get attention of administrators and decision makers, it is important to highlight the necessity and potential of Internet accessible remote laboratories. It is important for the remote experiment community to arrange lectures and presentations in various forums so that it can get attention of the administrators and decision makers. I believe that the International Association of Online Engineering (IAOE) and other national and regional forums can take a leading role in this effort.

As we all know that need is a mother of all invention. With this respect industry sector is a major power house for the development of a new technology, if the industry can realize the potential benefit of this technology. The responsibility rests upon the remote experimentation community to highlight the possibility of use of remote experimentation for industry benefit. The awareness initiative (as mentioned in the previous paragraph) needs to be extended into the industry arena.

In terms of development of commercial products, there should be collaboration between academia and industry so they can launch projects that will design and prototype custom products that can be utilized in design of remote laboratories. With this respect one can look for federal, state, and company funding. In USA, there are funding opportunities for small business initiatives from federal agencies.

\section{REMOTE EXPERIMENT FACILITY}

The author has been working on remote experiment development and implementation for last ten years. During this period, he has attracted research and development grants from National Science Foundation (Federal funding agency in USA), academic institutions, and industries. Some of these developments are used to deliver experiment courses within an electrical engineering technology program. This section will provide an outline of those developments and their implementation outcomes.

\section{A. Design Philosopy}

To maximize the benefit of remote laboratories, the design philosophy includes a number of features: a) use of emerging technologies; b) individualized learning; c) knowledge-centered learning; d) embedded assessment strategies; and e) scaffolds.

Use of emerging technologies: The Internet is the basis of the developed environment and utilizes web and software technologies with which this generation of students is comfortable to work. This allows students and the faculty/facilitator to have $24 / 7$ access to the environment through readily available Internet browsers. In terms of computer interfacing and data handling, it uses emerging data acquisition systems and associated software for data collection, analysis, and interactive graphical user interface.

Individualized learning: The environment allows students to start from a point at which they are comfortable and move forward at their own paces. At present, the faculty/facilitator has set an experiment for a given topic and all the students perform this irrespective of their level of understanding. This philosophy is to simply shoot for the middle and hit most people's needs and does not serve students from either side of the ability spectrum. This individualized experiment encourage students from both ends of the ability spectrum to move forward. This kind of approach is also known as differential learning, in which students absorb content in a manner that best suits their abilities and academic needs [36].

Knowledge centered learning: Knowledge centered learning allows one to think and solve problems not simply due to a generic set of thinking skills but through wellorganized bodies of knowledge that support planning and strategic thinking. The system is designed to allow the students to transform information into knowledge and knowledge into judgment. These were infused during the design of experiment modules, examples, and throughout the evaluation process. Emphasis was given to sensemaking, helping students become metacognative by expecting new information to make sense and asking for clarification when it does not.

Embedded assessment: At the end of each experiment session, a student automatically presents with different test items, based on ability level and prior response. This allows monitoring and fostering of ongoing individualized improvement - not just high or low ratings, but growth rate as well. The assessment system supports both the faculty/facilitators and students [37].

Scaffolds: In the education field, expert practitioners can first model the activity while the learner observes, scaffold the learner with advice and examples, then guide the learner in practice, and gradually taper off support and guidance until the learner can do it alone [38]. Within the developed environment, the provision of scaffolding was incorporated so students can seek help when needed to explain a certain idea/concept/feature.

These features provide an engaging experiment experience, working with students pre-existing knowledge, and developing skills of self-monitoring and reflection, which contribute toward improving the quality of STEM education.

\section{B. Design Implementations}

Most of the implementations are done through two NSF grants (DUE-0442374 and DUE-0837138). This involves design development (hardware and software), pedagogical design, course implementations, and evaluation. This implementation proceeds through a number of inter-linked tasks covering a range of disciplines, which include computer interfacing, web design, interactive graphical user interface, computer networking, network/web security, experiment module designs, assessment strategy, and project evaluation. The project implementation can be divided into four main components: a) facility development; b) communications and software applications; c) pedagogical design; and d) evaluation.

The Facility: The developed facility can be presented by a generic architecture as shown in Figure 3 . The facility consists of six main components: 


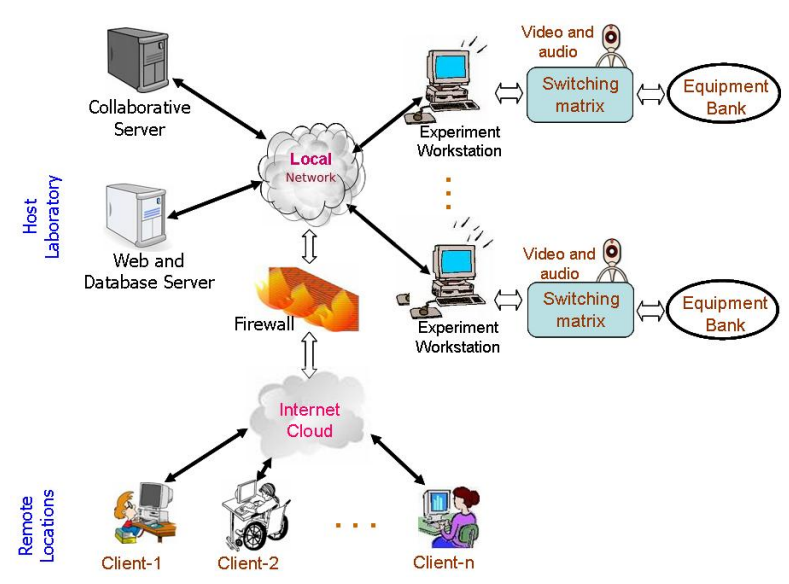

Figure 3. Proposed system block diagram.

1) web and database server; 2) collaborative server; 3) experiment workstation server; 4) switching matrix; 5) equipment bank; and 6) video, audio, and text message. The web and database server, collaborative server, and experiment workstations are connected to a local network, which is then tied up with the global Internet cloud via a firewall.

Web and database server- This allow the faculty/facilitator to a) integrate and configure experiments with the environment; b) create and manage user accounts; c) upload experiment guidelines, pedagogical and assessment tools, and survey questionnaires; d) activate/deactivate equipment; e) monitor student activities in terms of use of the experiment; and f) monitor assessment outcomes. Some of these features will be web-based and will allow the faculty/facilitator to perform those tasks over the web from any location. Along with other items, there is a database that contains all the pedagogical tools and resources, assessment items, user demographic data, password control data, user activity data (in terms of the use of the facility by individual users), student engagement data, and remote experiment utilization data. The database is dynamic and some of its content is updated automatically while the facility is in use. All these data are being linked with an XML file, so that they can be used by the environment. Users can access the XML files as data sources, as if they are accessing other databases. Each of the developed pedagogical tools and resources are considered an entity and is be marked with unique identification.

The technologies that were used for this module are extensible markup language (XML), simple object access protocol (SOAP), web services description language (WSDL), active server pages (ASP), .NET technology, and hyper text markup language (HTML) [39, 40, 41]. Based on the received remote instruction and using these technologies along with coordination with the database, this module structures data/information to display within the user's (client or faculty/facilitator) web page. The system is password protected and the protection is implemented by using currently available technologies that allow web browsers and web servers to communicate over a secured connection [42]. This facility addresses authentication, confidentiality, and integrity.

The collaborative server provides an integrated learning environment to facilitate remote working between groups of students or students and faculty. This server accommodates a collaborative working approach to allow educational institutions and training providers to provide re- motely located students with access to campus based experiment resources for remote experimentation augmented by live lectures and tutorials given by tutors. The environment allows faculty to create, manage, and deliver live lectures to a widely dispersed audience of students while allowing students to undertake real (non-simulated) practical exercises either individually or collaboratively. This collaborative functionality allows remote users to work together on the same experiment hosted on the same remote workstation simultaneously, while accessing, viewing and controlling each component of the integrated learning environment.

The experiment workstation is connected to the equipment bank via a switching matrix, along with a video camera and microphone. The switching matrix is connected to the experiment workstation via a custom built Input/Output (I/O) card with a sufficient number of analog and digital I/Os to provide connections for the equipment inputs and outputs. There are a number of experiment workstations connected with the equipment so that it can run multiple experiments that may be required for a experiment session.

The switching matrix is directly connected between the equipment bank and experiment workstation (Figure 4). This module is designed by using emerging switching hardware that is usually found in the telecommunication area. With the appropriate control signal, the switching mechanism provides a direct physical path dedicated to a single connection between one signal point (input/output) from an equipment to one of the ports of the I/O card.

One of the main components of the Internet accessible experiment facility is the GUI (graphical user interface). This serves as the media link between the experiments and the clients. It is important to provide a user-friendly, effective GUI that attracts clients while performing experiments without the physical supervision and assistance usually provided during a traditional experiment class. All the inputs and outputs of the equipment were connected to the switching matrix module. A client is able to command the switching matrix to connect appropriate equipment input and output to the appropriate ports of the I/O card to obtain a connection configuration for a desired experiment.

The equipment bank consists of the equipment that is to be used for the experiment course. All equipment is connected to the switching matrix and can be configured for almost any experimental arrangement (limited by prohibiting any undesired configuration for safety and protection). Here the faculty/facilitator is not pre-fabricated or assembled in any experiment for the students; students themselves assemble their experiment. This provision provides students with much more freedom to play with and de-

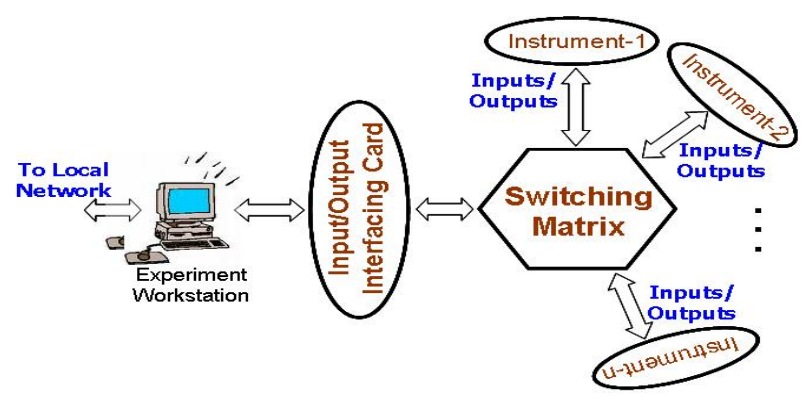

Figure 4. Layout of the switching matrix. 
velop their experiment skills. This kind of arrangement is new to the remote experiment area, and lack of this capability is one of the major reasons why remote laboratories are not gaining popularity.

Video and audio parts have a video camera and a microphone. Performance of some experiments may produce a physical motion and sound. A video camera with pan, tilt, and zoom capability allows a client to monitor a physical motion for a given experiment. In addition to a graph and plot, a video enhances the learning process for the clients. A microphone is also useful to hear any sound effect that may be produced by an experiment (such as a running motor or an alarm, etc).

Figure 5 shows a flowchart for various activities that can be performed using this facility. The environment homepage provides a project information dissemination platform as well as a login facility. The technologies that are used for this module are extensible markup language (XML), simple object access protocol (SOAP), web services description language (WSDL), active server pages (ASP), .NET technology, and hyper text markup language (HTML) [39, 40, 41]. There are two levels of access to the environment. One is for the client (student) and the other for the supervisor (faculty/facilitator).

In the client access mode, it allows a client to a) assemble an experiment using the equipment connected to the system; b) customize a graphical user interface using various kinds of graph window, tabular data window, and video window, and audio; c) perform an experiment and visualize the result of the designed experiment; d) take an assessment test after a experiment session; e) observe his/her own progress as well as the progress of the whole class (in terms of learning outcomes); and f) provide feedback about the system itself (through a survey). The 'Instructions' document includes both the text and movie (with audio) to demonstrate the use of the environment. Special care will be taken to highlight all the necessary steps that one needs to do to perform an experiment, assessment activities, and survey.

The experiment modules provide details of the scope of a experiment course, description of the equipment used, and how they can be configured to assemble various experiments to achieve course objects.

In the supervisory access mode (Figure 5), one can view clients' activity data and incorporate/modify assessment items, documents for experiment modules as well as instructions. One of the important features within the supervisor access is the client activity, in which the faculty/facilitator can track an individual student in terms of use of this environment, personal growth, and the growth of the whole class. Within the environment, arrangements are made to collect assessment data, learning behavior and engagement data, and facility performance data. Web application software is developed to analyze the data automatically so the faculty/facilitator can view the findings on a real-time basis. This feature allows the faculty/facilitator to take appropriate action for update/modification of the experiment modules, assessment items, and instruction or any other aspect of the environment.

Pedagogical design: The objectives of a traditional program expect that for a given experiment course, a student should achieve his/her highest level at the end of the semester and a grade will be allocated on that basis. Consid- ering the target courses that are parts of a traditional program, and although each student progresses at his/her own learning pace, efforts were made for each student to achieve his/her highest level at the end of each topic within a given period of time. The pedagogical tools within the developed environment, learning at their own pace, and information on personal and class achievement levels will encourage students to achieve their highest potential [43].

Each week the faculty/facilitator publishes a 'Experiment module' document through the web page. This document provides the identified objectives for that week along with a description of possible of experiments (with detailed diagrams and instructions) that one can perform to achieve those objectives. In addition, students can use the provided experimental design or develop their own design and perform these as many times as they like. At the end of each week there is an assessment activity based upon that week's objectives [44].

There are various pedagogical design strategies that one can utilize for a experiment course design [45]. To materialize the system design philosophy, the pedagogical design involves a blended learning approach by synergic combination of three components: face-to-face instruction, cognitive apprenticeship, and discovery learning [46, 40] (Figure 6).

Face-to-face instruction was delivered using traditional approaches while the remaining two components were implemented through the proposed environment. Each student has a personalized leaning environment that provides feedback for personal achievement level along with his/her standing within the class.

Face-to-face instruction: is a systematic method for familiarizing the students with experiment equipment and their working principles. The class meets twice at the beginning of the semester and the faculty/facilitator describes the experiment equipment they are going to use for their remote experiment exercises. To ensure their level of

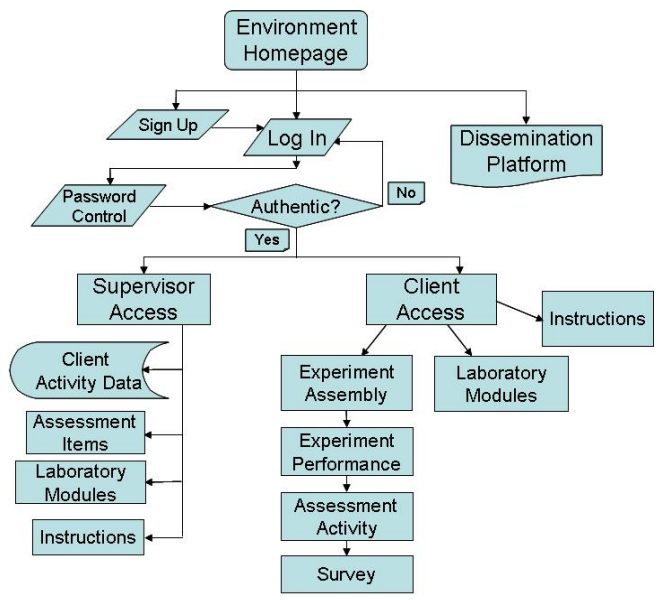

Figure 5. Flowchart for server module activities.

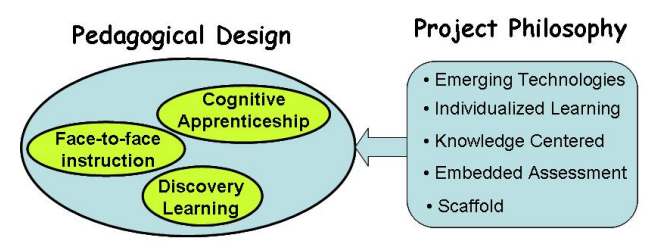

Figure 6. Pedagogical model in light of project philosophy. 
understanding, the class has small group discussions followed by an organized assessment test. The operation and working principle of the remote experiment environment will also be demonstrated to the students, so they can have an idea about the working principle of the environment. Students also use the remote experiment environment from other Internet connected computers within the same experiment (where the remote experiment facility is located) and observe the changes at the remote experiment end. The target experiment courses complement corresponding lecture classes and students have the opportunity to meet with the faculty/facilitator at least twice a week during their lecture classes, during which they can discuss any remote experiment course related issues.

Cognitive apprenticeship: is a method primarily used for teaching processes that experts use to handle complex tasks. The focus of this learning-through-guidedexperience is on cognitive and metacognitive skills. Applying apprenticeship methods to largely cognitive skills requires the externalization of processes that are usually carried out internally. Observing the processes by which an expert listener or reader thinks and practices these skills can teach students to learn on their own. In this project, texts, animations, and voices are used to develop tools for cognitive apprenticeship to elaborating on a theme, idea, or concept. These tools present the features, purposes, and use them in a practical manner through modeling, coaching, articulation, reflection, and exploration.

Discovery learning: is an approach of instruction through which students interact with their environment by exploring and manipulating objects, wrestling with questions and controversies, or performing experiments [47]. The idea is that students are more likely to remember concepts they discover on their own [48].

Please note that the pedagogical design proposed for this project is specifically developed considering the nature of the target courses. It will be the faculty/facilitator's prerogative to choose a suitable pedagogical design considering the nature of a given experiment courses activities. As an example, if this environment is going to be used for a distance learning program for mature students, then the design will be different from the one presented within this proposal.

\section{EVALUATION}

One of the major aims of the project was to assess the effectiveness of the developed facility as well as evaluate the student learning outcomes. To address these issues the evaluation process is divided into four parts: a) assess students' learning outcomes; b) assess students' learning behavior in terms of the access time and duration of use (in terms of the use of the facility); c) assess the effectiveness of the facility and students' perception about the facility; and d) assess ethical issues. The first two are achieved through quantitative analysis, while the last one is done through qualitative analysis. Professor Herbert J. Walberg, Research Professor of Education and Psychology at the University of Illinois at Chicago and Visiting Professor at Stanford University, acted as the external evaluator for the project. He is a world renowned scholar and researcher in teaching psychology and evaluation. Dr. Walberg has advised on questionnaire design, evaluation of the pedagogical effects of the system, data analysis, and interpretation.

\section{A. Students Learning Outcomes}

To assess student learning, the class was divided into a control group and test group. The control group took the course using an existing traditional experiment, while the test group performed the experiments developed through the remote experiment facility. The test group was composed of male and female students with diverse ethnicity and mixed educational abilities. Both the groups were tested with pre- and post-tests, and the results were compared for any difference. It was observed that there were statistically significant differences between pre- and post tests for both the test and the control groups, with the observed that these differences for the test group and the control group were not statistically different based on twotail and non-paired t-tests. It can be interpreted that both the test group and the control group learned effectively and the difference between the two groups was not significant.

\section{B. Students Learning Behavior}

To assess students' learning behavior in terms of the access time and duration of use, the developed facility has in-built capacity to collect students' login and logout times along with the time taken to perform each experiment. These data allowed the facilitator to know the level and timing of facility use and hence provided a broader understanding of the students' behavior in terms of use of the facility.

These data allowed comparing the leaning efficiency of the control group and the test group and also the students' behavior in terms of the use of the facility. It was found that there were statistically significant differences between the test and the control groups in their time spent on the experiment tasks, with the test group spending 67\% less time than the control group on the average. It can be interpreted that the test group learned more efficiently than the control group. In terms of access time to the facility, it was found that the time of the day when students in the test group performed their experiment tasks ranged between 9:00 a.m. and 1:00 a.m. of the next day, which is a duration of 16 hours, indicating great flexibility and convenience for students that is otherwise impossible because of the cost and administrative limitations under a traditional experiment configuration. Figure 7 shows the access profile to the remote experiment experiments.

These data allow comparing the leaning efficiency of the control group and the test group and also the students' behavior in terms of the use of the facility. It has been found that there are statistically significant differences between the test and the control groups in their time spent on the experiment tasks, with the test group spending 67\% less time than the control group on the average. It can be interpreted that the test group learned more efficiently than the control group. In terms of access time to the facility, it has been found that the time of the day when students in the test group perform their experiment tasks range between 9:00 a.m. and 1:00 a.m. of the day, which is a duration of 16 hours, indicating great flexibility and convenience for students who are otherwise impossible because of the cost and administrative limitations under a traditional experiment configuration. Figure 6 shows the access profile to the remote experiment experiments. 


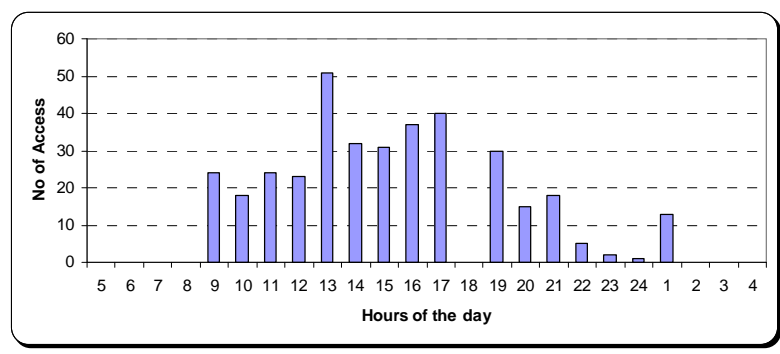

Figure 7. Shows the access profile to the facility in terms of time of the day.

\section{Effectiveness of the Remote Facility}

The third evaluation issue was to assess the effectiveness of the facility and students' perception about the facility. This has been done through a weekly survey along with a descriptive statement from the test group students at the end of the semester. The remote experiment course is a new concept, and evaluation of the facility for its usefulness will provide an understanding in terms of the students' points of view. Toward this, a weekly survey is incorporated within the facility that students need to complete at the end each experiment session. The questions are designed in such a way that they allow the facilitator to get an understanding about the facility's performance in terms of accessibility, user friendliness, logical arrangement of the information provided, and level of attraction with the web presentation. Students were queried regarding their interest level in the material, adequacy of background preparation, usefulness of the handouts, effectiveness of the tutorials, knowledge acquired from each topic, relevance of course materials, ease of access to the Internet facility, and suggestions for improvement. The collected data have both short term and long term use. As a short term use, the responses were reviewed by the facilitator on a weekly basis and were modified, upgraded, or altered through improvement/updating of the teaching materials, experimental facility, and delivery approach. The long term use involves the quantitative analysis of the collected data for a complete semester and a review to identify the aspects of the facility that can be enhanced for future developments.

The survey result shows that in general students liked the system and found the arrangement useful. However, in terms of learning, they found that the remote experiment is almost same as the traditional lab arrangement. Students also found the system was easy enough to operate. For the descriptive statement, each test group student wrote a descriptive statement on their personal view towards the remote experiment, benefits of the remote experiment, and what can be done better for the future. The main benefit pointed out by almost all the students is the anywhere anytime feature of the remote experiment facility. This allows them to perform experiments at times of their own choice that fit their busy work schedule. Some students raise the point that the remote experiment does not provide any hands-on experience. This is true, but much research shows that, other things being equal, hands-on experiment experience does not add knowledge and understanding beyond non-experiment instruction. Mastering particular apparatus in a experiment, moreover, may not be applicable to other apparatus and circumstances. A few mentioned the tight schedule for pre- and post-experiment submission. Considering the junior level undergraduate course (where all of their labs and course works are closely supervised), the remote experiment is a major responsibility, and some of them are not totally comfortable to deal with this.

\section{CONCLUSIONS}

The paper provides a discussion on the issues that need to be addressed to make the Internet accessible remote experiment facility sustainable and acceptable by the academic community. The main factors are modularity issue in design, commercial products and systems that can support the development process, and gather support from administration.

The second part of the paper presents a remote experiment design strategy and their use for offering a number of experiment courses. The evaluation process during this course offering provides a valuable insight in terms of effectiveness of remote experiment systems.

\section{REFERENCES}

[1] Atkinson, R. (1968). Computerized instruction and the learning process, American Psychologist, 23, pp.225-239. doi:10.1037/h0020791

[2] Suppes, P. and Morningstar, M. (1968). Computer-assisted instruction, Science, 166, pp.343-350. doi:10.1126/science. 166.3903.343

[3] Barron, B. J., Schwartz, D. L., Vye, N. J., Moore, A., Petrosino, A., Zech, L., and Bransford, J. D. (1998). Doing with understanding: Lessons from research on problem and project-based learning. The Journal of the Learning Sciences. 7, pp.271-311. doi:10.1207/s15327809jls0703\&42

[4] Mott, R. L., Neff. G. P., Stratton, M. J., and Summers, D. C. S. (2002). Future directions for mechanical manufacturing, and industrial engineering technology programs, Journal of Engineering Technology, 19(1), pp.8-15.

[5] Scott, J. (2003). A vision for online kindergarten learning community, Technological Horizons in Education, 30(7), pp.40-43.

[6] Patton, J. B. and Jayanetti, P. (1996). The making of multimedia power systems control of simulation Labware, IEEE Transactions on Education, 39(3), pp.314-319. doi:10.1109/13.538753

[7] Briller, V. and Carpinellin, J. D. (2002). A comparative analysis of student performance in lower division computer science courses in face-to-face mode versus distance learning mode, Proceeding of the ASEE Annual Conference \& Exposition (Computers in Education Division), Vive Le Engineer, Montréal, Quebec, Canada, June 16-19.

[8] Kariya, S. (2003). Online education expands and evolves, IEEE Spectrum, May, pp.49-51. doi:10.1109/MSPEC.2003.1200179

[9] Poindexter, S. E. and Heck, B. S. (1999). Using the web in your courses: What can you do? What should you do?, IEEE Control Systems Magazine, 19, pp.83-92. doi:10.1109/37.745773

[10] LaPorte, J. (2001). Online learning needs in technology education, Journal of Technology Education, 13(1), Fall 2001.

[11] Nguyen, J. and Paschal, C. B. (2002). Development of online ultrasound instructional module and comparison to traditional teaching methods, Journal of Engineering Education, 91(3), pp.275-283.

[12] Eskey, M. T. (2002). Recruiting distance learning: eArmy program helps keep soldiers educated, Technological Horizon in Education Journal, December, pp.31-34.

[13] Nebolsky, C., Yee, N. K., Petrushin, V. A., and Gershman, A. V. (2003). Using virtual worlds for corporate training, Proceedings of the $3^{\text {rd }}$ IEEE International Conference on Advanced Learning Technologies, July 09-11, Athens, Greece.

[14] Virvou, M. and Katsionis, G. (2003). VIRGE: Tutoring English over the web through a game, Proceedings of the $3^{\text {rd }}$ IEEE International Conference on Advanced Learning Technologies, Athens, Greece, July 09-11.

[15] Chen, Y -C. and Naughton, J. M. (2000). An undergraduate experiment platform for control system design, simulation, and im- 
plementation, IEEE Control Systems Magazine, June, pp.12-20. doi:10.1109/37.845034

[16] Ng, K. H. and Komiya, R. (2002). Multimedia textbook for virtual education environment, Engineering Science and Education Journal, April, pp.73-79. doi:10.1049/esej:20020206

[17] Azad, A. K. M., Tokhi, M. O., and Shaheed, M. H. (2007). A Software Environment for Intelligent Modeling and Simulation of Flexible Manipulator Systems, Computers in Education Journal, 17(4), pp. 86-103.

[18] Azad, A. K. M. (2008). Interactive Web-based e-learning for Studying Flexible Manipulator Systems, International Journal of Online Engineering 4(3), pp. 5-12.

[19] Bengu, G. and Swart, W. (1996). A computer-aided total quality approach to manufacturing education in engineering, IEEE Transactions on Education, 39(3), pp.415-422. doi:10.1109/13.538767

[20] Hagg, S. and Palais, J. C. (2002). Engineering online: Assessing innovative education, Journal of Engineering Education, 91(3), pp.285-289.

[21] Richards, L. G. (1997). Distance education: Realizing its potential, International Journal of Engineering Education, 13(1), pp.6-12.

[22] Boyle, A. P., Bryon, D. N., and Paul, C. R. C. (1997). Computerbased learning and assessment: A palaeontological case study with outcomes and implications, Computers and Geosciences, 23(5), pp.573-580. doi:10.1016/S0098-3004(97)00025-3

[23] Grose, T. K. (2003). Can distance education be unlocked, PRISM, April, pp.19-23.

[24] Palais, J. and Javurek, C. G. (1996). The Arizona State University electrical engineering undergraduate open experiment, IEEE Transactions on Education, 39(2), pp.257-264. doi:10.1109/13.502073

[25] Henson, A. B., Fridley, K. J., Pollock, D. B., and Brahler, C. J. (2002). Efficacy of interactive internet-based education in structural timber design, Journal of Engineering Education, 91(4), pp.371-387.

[26] Cooper, M. (2005). Remote laboratories in teaching and learning issues impinging on widespread adoption in science and engineering education, International Journal of Online Engineering, 1(1), pp.1-7.

[27] Swearengen, J. C., Barnes, S., Coe, S., Reinhardt, C., and Subramanian, K. (2002). Globalization and the undergraduate manufacturing engineering curriculum, Journal of Engineering Education, April, pp.255-261.

[28] Burgess, L. A. (2003). WebCT as an E-learning tool: A study of technology students' perceptions, Journal of Technology Education, 15(1).

[29] Esche, S. K. (2001). Remote experimentation - one building block in online engineering education. Invited presentation at the 2001 ASEE/SEFI/TUB International Colloquium on Global Changes in Engineering Education, Berlin, Germany, September, pp.15-18.

[30] Esche, S. K. and Hromin, D. J. (2001). Expanding the undergraduate experiment experience using web technology. Proceedings of the 2001 ASEE Annual Conference and Exposition, Albuquerque, New Mexico, June 24-27.

[31] Hites, M. (2002). Creating and running undergraduate experiments controlled through the internet, Proceedings of the IL/IN Conference of American Society of Engineering Education, April 12, pp.192-198.

[32] Restivo, M.T. and Silva, M.G., (2009) Portuguese Universities Sharing Remote Laboratories, International Journal of Online Engineering, 5, pp. 16-19.

[33] Henke, K., Ostendorff,T., and Mitschele-Thiel, A. (2009) Mobile Prototyping Platforms for Remote Engineering Applications, International Journal of Online Engineering, 5, pp. 35-42.

[34] Soumare, H., Shroff, R., Hardison, J. L., Alamo, J. A., Harward, V. J., Bailey, P. H., and DeLong, K. K. (2009). A Versatile Internet-Accessible Electronics Workbench with Troubleshooting Capabilities, International Journal of Online Engineering, 5, pp. 7280.
[35] Aliane1, N., Pastor, R., and Mariscal, G. (2010). Limitations of Remote Laboratories in Control Engineering Education, International Journal of Online Engineering, 6(1), pp. 31-33.

[36] Tomlinson, C.A. (2001). How to differentiate instruction in mixedability classrooms, $2^{\text {nd }}$ ed. Alexandria, VA: Association for Supervision and Curriculum Development.

[37] Nitko, A. J. (2004). Educational Assessment of Students, $4^{\text {th }}$ Edition, Prentice Hall, New Jersey.

[38] Rogoff, B. (1998). Cognition as a collaborative process. In W. Damon (Series Ed.) \& D. Kuhn \& R.S. Siegler (Vol. Eds.) Handbook of child psychology: Vol. 2. Cognition, perception, and language (5th ed.). New York: Wiley.

[39] Erl, T. (2004). Service-Oriented Architecture: A Field Guide to Integrating XML and Web Services, Prentice Hall, ISBN 0-13142898-5.

[40] Graham, C.R., Allen, S. \& Ure, D. (2005). Benefits and challenges of blended learning environments. In M. Khosrow-Pour (Ed.), Encyclopedia of information science3 and technology pp. 253-259. Hershey, PS: Idea Group.

[41] Weerawarana, S., Curbera, F., Leymann, F., Storey, T., and Ferguson, D. F. (2005). Web Services Platform Architecture: SOAP, WSDL, WS-Policy, WS-Addressing, WS-BPEL, WS-Reliable Messaging, and More, Prentice-Hall, ISBN 0-13-148874-0.

[42] Installing and Configuring SSL Support (2003). web site: http://java.sun.com/2 webservices/docs/l.l /tutorial/doc/WebAppSecurity5.html, (last viewed on $2^{\text {nd }}$ May 2009).

[43] McCray, R. A., DeHann, R. L., Shuck, J. A., Editors; (2003). Improving Undergraduate Instruction in Science, Technology, Engineering, and Mathematics, National Research Council.

[44] Fox, M. A. and Hackerman, N., Editors, (2003b). Evaluating and Improving Undergraduate Teaching, National Research Council.

[45] Ryder, M. (2006). Instructional Design Models, University of Colorado at Denver School of Education, http://carbon.cudenver.edu/ mryder/itc_data/idmodels.html\#comp arative, (last viewed on $2^{\text {nd }}$ May 2009).

[46] Graham, S., Davis, D., Simeonov, S., Daniels, G., Brittenham, P., and Nakamura, Y. (2005). Building Web Services with Java: Making Sense of XML, SOAP, WSDL, and UDDI, Prentice-Hall, ISBN $0-672-32641-8$.

[47] Ormrod, J. (1995). Educational psychology: Principles and applications. Englewood Cliffs, NJ:Prentice-Hall.

[48] Roblyer, E., and Havriluk, M.D., Edwards, J., and Havriluk, M.A. (1997). Integrating Educational Technology into Teaching, Merrill, Upper Saddle River, NJ.

\section{AUTHOR}

Abul K. M. Azad is a Professor with the Technology Department of Northern Illinois University. His research interests include mechatronic systems and structural control, remote laboratory, adaptive/intelligent control, mobile robotics, and educational research. In these areas, Dr. Azad has over 100 referred journal and conference papers, edited books, and few book chapters. So far, he has attracted around $\$ 1.5 \mathrm{M}$ of research and development grants from various national and international funding agencies. He is active with various professional organizations along with editorial board member for a number of professional journals. He is a senior member of IEEE and ISA and a member of ASEE and IET. (aazad@.niu.edu)

Most of the design and development work reported in this paper are funded by the National Science Foundation under NSF Award Numbers DUE-0442374 and DUE-0837138.

Submitted July $12^{\text {th }}, 2010$. Published as resubmitted by the author July $20^{\text {th }}, 2010$. 